\title{
Re-searching the labyrinth of life-styles
}

\author{
Wim Heijs • Anne-marie van Deursen • Marieke Leussink • \\ Jos Smeets
}

Received: 12 July 2010/Accepted: 7 July 2011/Published online: 21 July 2011

(C) The Author(s) 2011. This article is published with open access at Springerlink.com

\begin{abstract}
This study evaluates three main assumptions underlying the belief that research on life-styles is essential to gain insight in the demand side of the housing market. First, traditional demographic and socioeconomic variables are thought to have become less adequate for predicting residential preferences because of the increased sociocultural complexity of contemporary society. Life-styles could provide the necessary additional information. Second, certain life-style groups supposedly prefer specific aggregated types of housing and environment (woonmilieus). Third, residents supposedly favor homogeneous life-style settings. These assumptions are not substantiated by the results of a survey among the tenants of a housing association in Eindhoven, the Netherlands. In the discussion it is argued that the findings may have a more general validity. Life-styles are probably not necessary as a supplement to traditional variables. Moreover, other additional predictors (specifically, single sociocultural characteristics and activities) appear to be less problematic and more suitable to account for the consequences of sociocultural diversity. These variables may also facilitate the understanding of housing preferences and thus further a better match between supply and demand.
\end{abstract}

Keywords Demand side $\cdot$ Housing market $\cdot$ Life-styles $\cdot$ Prediction · Residential preferences

W. Heijs $(\square) \cdot$ M. Leussink $\cdot$ J. Smeets

Real Estate Management and Development, Department of Architecture Building and Planning, Eindhoven University of Technology, P.O. Box 513, 5600 MB Eindhoven, The Netherlands e-mail: w.j.m.heijs@tue.nl

M. Leussink

e-mail: m.i.k.leussink@tue.nl

J. Smeets

e-mail: j.j.a.m.smeets@tue.nl

A. van Deursen

Domein (Housing Association), Eindhoven, The Netherlands 


\section{Introduction}

Until the 1990s, the principal aim of housing policy in the Netherlands was to overcome a shortage of dwellings. While a balance seemed to be reached in quantity, a qualitative discrepancy became apparent between demand and supply. The existing post-World War II housing stock did not match specific requirements regarding the dwelling and the environment. During the following years the variety of housing preferences became even greater, presumably because of the increasing sociocultural complexity of society. As a result, the demand side gradually became more important, and today the housing market is commonly regarded as demand-oriented (van Diepen and Arnoldus 2003; Smeets 2010).

Housing associations (and other providers such as local authorities and developers) are facing a significant challenge to reconcile the diversity of requirements on the demand side with a supply that has limited adaptability. In order to deal with this problem and adopt a more customer-oriented approach, organizational reform was needed. This paradigm shift included a modification of the management structure (less hierarchical and more processoriented) and changes in communication and information flows, both within the organization and in relation to the environment (Smeets 2010). In search of novel means to better appreciate the characteristics and requirements of their clientele, several housing providers introduced techniques that are derived from marketing, including life-style research.

In general, life-styles refer to regular patterns of manifest behavior, of certain latent factors influencing behavior (values, social or cultural backgrounds, knowledge, attitudes, preferences, etcetera) or of manifest activities mixed with their latent causes. These patterns typify certain groups or individuals in society. The concept has a long history, dating back to the early 1900s, and it is rooted in various disciplines (details can be found in e.g. Ganzeboom 1988; van Diepen and Arnoldus 2003; Heijs et al. 2005). In sociology, the emphasis has been on behavior that symbolizes the status and membership of social classes or, later in time, individual social identities. These are based on economic and cultural distinctions and serve as a guide in social interaction. In psychology, it was originally the unique internal structure of motives, traits, interests and values that was deemed to determine a personality and individual behavior. At present, life-styles refer to repeated behavior as well as the underlying factors. In social geography, life-styles indicate the prevalent and typical ways in which people spend their (restricted) time and financial resources. Marketing research employs the concept to identify target groups or market segments for purposes of product development, sales strategies and communication. Lifestyles in that field are commonly characterized as regularities in activities, interests, values and opinions, or as psychological states that lead to these regularities.

Life-style research in the area of housing is based on a similar variety of views. Sometimes it is clearly embedded in the geographical tradition (the allocation of resources), while in other cases the origin seems to lie in sociology, psychology or marketing (e.g. when the ingredients are both manifest behavior and latent variables). The main goal of such studies is to improve the explanation and prediction of housing needs or preferences and ultimately of behavior on the housing market. Life-style research is currently regarded as necessary for four reasons (de Jong 1996; Bastiaansen 1997; de Wijs-Mulkens 1999; van Diepen and Musterd 2001; Hagen 2001; van der Wouden and Kullberg 2002; van Diepen and Arnoldus 2003). First, traditional demographic and socioeconomic variables (such as age, household composition and income) may no longer suffice to describe the manifold target groups and their preferences in present-day society. Life-styles could be a supplement to planning models, alongside or instead of those traditional variables, because they represent the elusive social and cultural components that account for the 
increased differentiation. Secondly, a correspondence is presumed between life-styles and preferred aggregated types of housing and environment (in Dutch: woonmilieus). Information on life-styles may support the design of these environments and the selection of residents. Thirdly, homogeneous life-style clusters in a neighborhood are expected to be valued by the inhabitants, in particular by life-style groups, because they might facilitate daily life and prevent social conflicts. Finally, knowledge concerning life-styles could be useful in view of the growing competition on the housing market; the conceptualization would capture the emotions that are thought to play up in the process of dwelling selection.

\section{Problem statement}

The application of life-styles to housing research and policy is fraught with difficulty. The usefulness of the concept-and especially the non-scientific approach to life-style segmentation by a number of commercial agencies (initiated by providers) that now seems to imbue most of these studies - has frequently been criticized (van Diepen and Musterd 2001; Ouwehand 2001; Nio 2002; Pinkster and van Kempen 2002; van der Wouden and Kullberg 2002; van Diepen and Arnoldus 2003; Heijs et al. 2005, 2009).

The main objections that have been raised are the following. Starting with the abovementioned motives for conducting life-style research, it is concluded that most of the assumed advantages lack an empirical basis, thus casting doubt on its necessity. So far, no evidence has been presented in support of the assumptions mentioned earlier: that traditional variables are deficient or that life-styles are an essential addition; that life-style groups display systematic preferences for certain aggregated types of housing and environment; that people favor homogeneous life-style settings; or that emotions will prevail over rational considerations in the selection process. Secondly, the concept is too indefinite to be helpful. It is unclear whether life-styles are a manifest characteristic (behavior), a set of latent factors (inducing behavior) or a mixture of both. Nor is it clear which life domains or scale levels are covered (e.g. work or leisure activities elsewhere, in addition to activities at home; the street level, the neighborhood or a wider range). Moreover, it is unclear which variables are part of life-styles and which are a cause or a consequence. Thirdly, the validity of life-style categories in commercial research is subject to debate. It is unlikely that cluster analyses performed with a large number of variables will produce exact group demarcations; there will be borderline cases (people who do not fit exactly into one of the limited number of profiles). No account is taken of possible differences in lifestyle between members of a family, nor of possible changes in life-style over the years. Validity checks are rarely provided. This type of research seems to contradict its initial goal by adopting a static and simplified view of society in order to convey its dynamic and complex nature.

In one literature review these difficulties have led the reviewer to conclude that much of the current life-style research in the field of housing resembles a labyrinth with no easy way out, an avenue of enquiry that should be entered with great caution and perhaps not at all (Heijs et al. 2005, 2009). This conclusion, however, was based on the absence of data supporting the necessity of life-styles and of a sharp definition of the subject. It is not derived from empirical evidence to the contrary (i.e. data showing that life-styles may in fact not be so necessary to an explanation). Recently a housing association in Eindhoven (Domein) requested our group to conduct a satisfaction survey among their tenants. This survey was also intended to investigate whether a life-style approach could contribute to the transparency of information on tenants within the organization and to the communication 
with future residents about the social environment they would choose to live in. This assignment provided an opportunity to study the legitimacy of three assumptions underlying the claim that life-style research is vital (van Deursen and Leussink 2010). The questions in this 're-search' of the labyrinth are:

1. To what extent are life-styles necessary for explaining and predicting housing preferences?

2. How strong is the relationship between life-styles and preferred aggregated types of housing and environment (woonmilieus)?

3. To what extent do life-style groups prefer homogeneous life-style settings?

\section{Methodology}

The methodology used in this research project requires a more detailed explanation. That is mainly because the operationalization of life-styles is not self-evident due to their indefinite nature and the unclear terminology. This issue is considered first. Then the research design is discussed together with the other variables.

\subsection{Operationalization of life-styles}

The research literature shows a wide diversity of life-style classifications with regard to their meaning, the number and names of life-style groups, and the variables these lifestyles are based on (Heijs et al. 2005, 2009). As was already pointed out, life-styles can refer to regular patterns in manifest behavior, latent variables or both, to different life domains and various scale levels. The procedures for deriving life-styles from the underlying variables differ as well. Life-styles may be formed from combinations of the values of a limited selection of variables in a conceptual model that is derived from theory or research (e.g. Reijndorp et al. 1997; Brouwer 1998; van Diepen and Musterd 2009). In such cases, the intended groups are known beforehand and group members share the same life-style. Other researchers (mainly commercial agencies) subject a large number of variables to cluster analysis or multidimensional scaling. Proximities of variables or values constitute patterns that represent the life-styles (e.g. Hagen 2001). These groups are not known in advance. Their homogeneity may be a problem because each additional variable increases the probability that individual characteristics will not match those of others in a group. When borderline cases are still considered group members (which seems to be common practice), the growing diversity may hamper the discernment of meaningful relations with residential preferences. By either method, life-style classifications usually vary across studies because of the different perspectives and sets of variables employed. Finally, the terminology is sometimes confusing. Terms like life-style variables or lifestyle characteristics may, for instance, stand for group names, variables that serve to construct life-styles, or other characteristics that are correlated with these variables or that are merely associated with the concept of life-style (sometimes including common demographic or socioeconomic features like income or age; see below).

In this study, a 'life-style definition' contains a description of the patterns represented by a particular life-style classification (manifest, latent or otherwise). 'Life-styles' refer to the groups in a life-style classification. This classification is a composite variable. The single variables that make up the classification and that are used to construct the life-styles and to identify group members are called 'indicators'. These single variables are part of 
life-styles because the groups are based on the information that is contained in those variables. Other variables may be related but, strictly speaking, they do not belong to lifestyles. Thus, the purport of a life-style classification will depend on the definition and the selected set of indicators.

The life-styles that were to be used in the current project were composed in advance by the housing association. They used yet another procedure. The initiative to develop a lifestyle approach for internal and external communication (see Sect. 2) included a series of meetings with professionals who were well acquainted with the tenants and their home situation (i.e. community workers, neighborhood coordinators and neighborhood consultants). The professionals tried to classify the population of tenants on the basis of their social behavior (having contacts with others or being withdrawn), leisure activities, the way the environment is being looked after, and the expectations that others will show the same type of behavior. The result of these meetings was a classification with eight lifestyles (see Table 1; van Deursen and Leussink 2010).

Considering the way these life-styles were obtained and the descriptions provided by the housing association, it was concluded that it is the best option to define them as patterns of manifest behavior. With regard to the operationalization of the life-styles in this study, the fact that the groups are known would seem to suggest a model-based approach, even though they do not stem from theory or research but from the daily experience of professionals. It is unclear whether practice is a better or a worse source compared to theory or empiricism. The subjective nature could be a negative aspect but the groups so constructed may also be a closer approximation of reality than those that are based on a model. Another difference from a model-based approach is that the indicators are not known. They have to be chosen in line with the life-styles provided by the housing association.

Life-style studies in the field of housing yield a vast array of possible indicators. Some employ traditional demographic and socioeconomic variables such as age, education, household composition, type of dwelling or location, occupation, income and labor market participation (Vijgen and van Engelsdorp Gastelaars 1986; Bastiaansen 1997; Brouwer 1998; van Diepen and Musterd 2009). These variables are unsuitable here because they would confound the analysis of the necessity of life-styles relative to traditional variables. Psychological values are also often regarded as indicators, but their use appears to be less suitable as well. Prevailing attitude-behavior theories in social psychology show that behavior is the product of a complex process involving a range of intermediate variables, including (in reverse order) behavioral intentions, attitudes or preferences, beliefs and general factors like knowledge, values and emotions (Ajzen 1991, 2001). Due to these transitional steps, and also to contextual influences of the situation and personality traits, the relations between psychological values and behavior appear to be rather indirect and

Table 1 Life-styles among tenants according to Domein Housing Association

\begin{tabular}{ll}
\hline Passers-by & Autonomous, to be left alone, not attached, residing for shorter period of time \\
Quiet citizens & Socially withdrawn, attached to place, not participating in activities \\
Mediators & Socially involved, neighborhood oriented, organizing and joining activities \\
Assertive citizens & Easily bothered, speaking out, demanding enforcement of laws and rules \\
Innovators & Initiating, independent, progressive, embracing new developments \\
Socially unrelated & Socially involved but not neighborhood oriented \\
Socially attached & Conservative, many contacts, attached to neighborhood, long-term residents \\
Subculture groups & Conservative, in-group focus, group norms, resisting outside social control \\
\hline
\end{tabular}




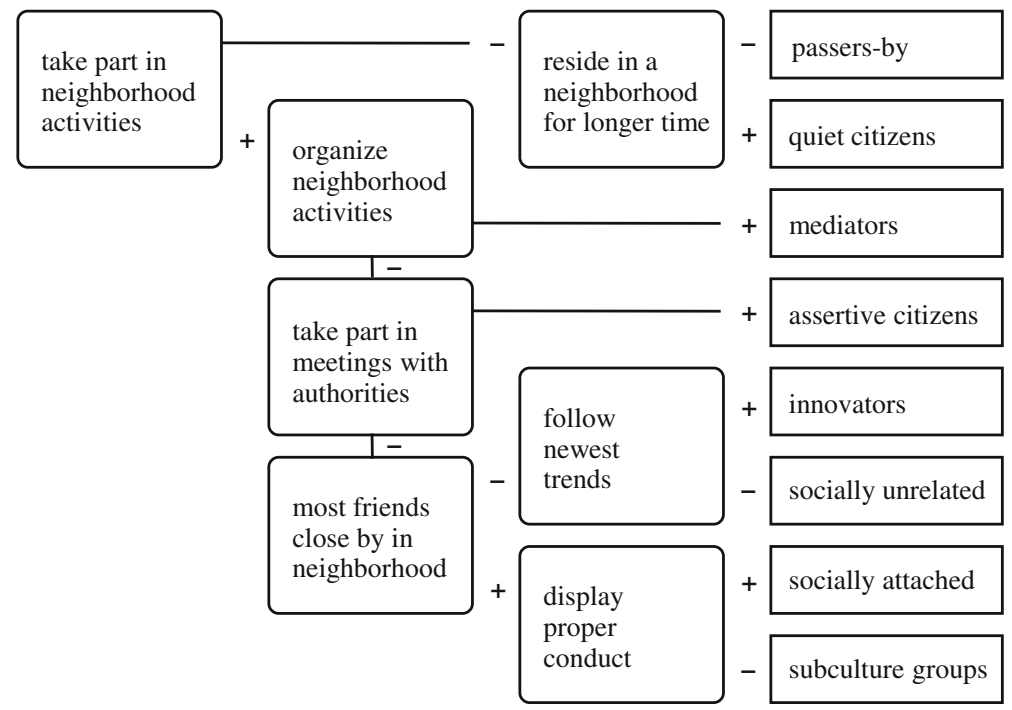

Fig. 1 Behavioral intentions and composition of the life-style groups

not very robust (Kahle et al. 1986; Kahle and Chiagouris 1997; Maio et al. 2003). These same theories indicate that behavioral intentions do qualify as indicators because they are the closest approximation of behavior apart from observing the actual behavior itself (which is, of course, impossible in this case).

In consultation with the housing association 17 behavioral intentions were formulated matching the group descriptions. They were phrased as genuine intentions to perform a certain behavior under suitable circumstances. A classic model-based method to establish life-style groups with this amount of indicators is unfeasible because of the number of combinations and the odds that some combinations are less realistic. Thus, an alternative and novel method was devised, based on the notion that a group should not necessarily be identified by all the available indicators simultaneously. Some life-styles may be distinguished using a different or a subsequent set. This has led to a taxonomy method with a shortlist of seven consecutive indicators (see Fig. 1; this bears some resemblance to biological labeling). The answers to the corresponding questions will lead up to particular groups. For instance, when someone intends to take part in neighborhood activities, does not intend to organize such activities but will actively join meetings with authorities, that person will more than likely belong to the group of assertive citizens. The other 10 intentions served as validation markers of group membership.

\subsection{Research design}

The conceptual relations that need to be analyzed to answer the research questions are shown in Fig. 2. To study the necessity of life-styles, the first step is to assess the association between residential preferences and the variables that are traditionally being used as predictors (a). Assuming that these predictors fall short due to the sociocultural complexity of contemporary society, this set should be supplemented by other variables that represent these (new) sociocultural elements. In keeping with the claim that life-styles are needed to account for the subsidiary diversity of preferences, that variable should be added. However, the 


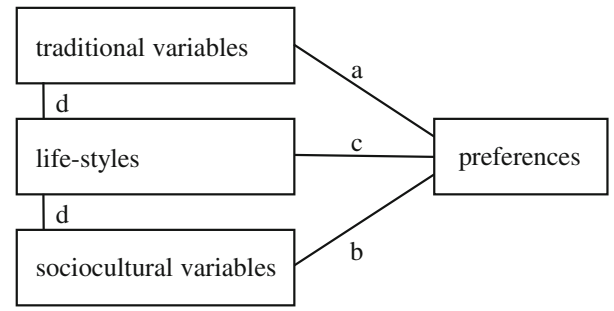

Fig. 2 Conceptual relations

previous discussion shows that the validity and generalizability of the composite variable life-styles are highly questionable, mainly because of its changeability. There is an alternative, namely the addition of single sociocultural variables which could characterize the increased complexity of society as well (e.g. political orientation, religion, ethnicity and preferred leisure activities). From a logical, practical and methodological viewpoint the use of a concise set of single variables should be examined first, provided that they are more trustworthy (i.e. easy to define and to convert into a valid and reliable measurable form). Therefore, the second step is the inclusion of a set of sociocultural variables (b). Next, lifestyles are added to study their supplementary impact (c). Given their definition (behavioral patterns) and indicators (behavioral intentions), these life-styles differ from the sociocultural variables. When the inclusion of life-styles at this point significantly improves the prediction rate, this outcome would constitute a clear indication of their necessity. Life-styles are generally not entirely independent of other predictors. An analysis of the mutual relations (d) allows more insight in the common and unique effects of life-styles on residential preferences. It may also help to interpret the nature and possible causes of these relations.

The second research question can be answered by studying the link between life-styles and the preferences for aggregated housing situations and types of environment (or woonmilieus) instead of separate characteristics (c). Finally, the third question requires verification of the relation between life-styles on the one hand and items in the survey measuring the perceived importance of homogeneous versus heterogeneous life-style settings on the other hand (c).

\subsection{Operationalization of the other variables}

The traditional and sociocultural variables were assembled from previous studies on residential satisfaction and housing-market behavior by a research institute that is part of the university. The first set consists of the usual demographic and socioeconomic characteristics (household composition, gender, age, income, level of education, occupation, main daily activity) and the present housing situation (location, dwelling type, year of construction, rent level). The second set contains political and religious orientation, nationality, ethnic/cultural background, a comprehensive list of leisure activities, and media use (internet, newspapers, television channels, programs, TV guide). These data are collected for the head of the household and a partner, if any.

Residential preferences (the dependent variables) include features of the dwelling (type, number of rooms, lay-out, sanitation facilities, outside space, ownership, rent level or purchase price) and the neighborhood (location, functional diversity, an inclusive range of services and of physical and social attributes). The aggregate preferences for the second research question consist of the type of dwelling, the neighborhood location, and the types 
of residential environment (woonmilieus) in the official classification of the city of Eindhoven. The preferences are measured as classificatory variables or with 4-point rating scales measuring the importance of these features. They should reflect concrete choices and not ideal ones. Since most respondents will not have plans for relocation, it was suggested that they assume an upcoming move and select the preferred options considering only the available financial resources and no other constraints. They should name attributes of the present situation when those attributes resemble the preferred circumstances.

\section{Analysis and results}

\subsection{Sample}

The survey took place in 2009 in Eindhoven and the neighboring villages Son \& Breugel and Best. All 5932 tenants of Domein were contacted and 2358 responded (39.8\%). The sample is representative of the population with regard to location and the year of construction of the dwellings. Other variables show some deviation from the expected frequencies (the first percentage given below indicates the real proportion and the second the expected one). There are relatively more elderly respondents (aged $\geq 65 ; 37(28) \%$ ) and fewer younger respondents (aged $\left.<44 ; 27(39) \% ; \chi^{2}=167 ; \mathrm{df}=5 ; P<.001\right)$. More women completed the form (54(46)\%; $\chi^{2}=59$; df $\left.=1 ; P<.001\right)$ and there are more two-person households compared to other types of family $\left(34(20) \% ; \chi^{2}=148 ; \mathrm{df}=4 ; P<.001\right)$, slightly fewer apartment buildings without an elevator $(14(18) \%)$ and more bungalows $\left(4(3) \% ; \chi^{2}=39\right.$; df $=4$; $P<.001)$. This information indicates that more questionnaires have been returned by older households; they may have had more time and willingness to participate, which is a common trend in survey research. More important is the relative scarcity of migrants $\left(\chi^{2}=525\right.$; $\mathrm{df}=1 ; P<.001)$. These households may be more reluctant to take part in surveys, though language may also have been a problem. As a result, it was decided to restrict the analyses to residents with a Dutch passport or a dual nationality $(\mathrm{N}=2,301)$. It is not likely that this affects the frequencies of life-styles because the excluded group is small and the sample still contains people with a foreign nationality.

\subsection{Life-styles}

With the taxonomy approach, all respondents with valid answers to the relevant questions can be classified in life-style groups. There are no borderline cases. Due to non-response, however, the number of suitable cases dropped to 2224. The intentions serving as validation markers did not reveal any inconsistencies, so the classification is considered to be sufficiently accurate (van Deursen and Leussink 2010). Quiet citizens are most frequent $(953 ; 41 \%)$, followed by mediators $(478 ; 20 \%)$ and socially unrelated citizens $(431 ; 18 \%)$. Less common are the socially attached $(145 ; 6 \%)$ and assertive citizens $(127 ; 5 \%)$. Innovators $(59 ; 3 \%)$, passers-by $(28 ; 1 \%)$ and subculture groups $(3 ; .1 \%)$ are only marginally present. Although it cannot be tested, these figures appear to be realistic in view of the composition of the population. Most tenants are fairly withdrawn (according to the housing association) and have lower incomes, which are probably not compatible with the pursuit of new trends. Usually, houses are rented for longer periods of time. People in subculture groups will generally constitute a minority and they are also less likely to participate in a survey. Because the latter three groups are too small from a statistical point of view, they are not included in the subsequent analyses. 


\subsection{Necessity of life-styles}

The detection of the necessity of life-styles requires several consecutive regression analyses for each preference. In this study, binary or multinomial logistic regression is used (depending on the number of choices) because most variables are categorical or do not have a normal distribution. The large number of preferences (55) and possible predictors (13 traditional variables, 46 sociocultural characteristics and 5 life-styles) can be a problem since multiple tests may increase the incidence of type I errors and multicollinearity. In order to lower these risks, the significance threshold $(\alpha)$ is set at .001 and the collection of variables is reduced in the following way. First, preferences are omitted when they are unrelated to the life-styles, based on $\chi^{2}$ tests and initial regression analyses as a backup, because in these cases life-styles are unlikely to be necessary for their prediction (note that this study is not intended to predict all these preferences; skipped preferences may well be predictable from the other variables). Second, the four-point rating scales measuring preferences are reduced to two categories (important or unimportant) to minimize the occurrence of low frequencies. Third, traditional and sociocultural predictors that may overlap are subjected to a $\chi^{2}$ test. If the result is significant, the one with the stronger linkage to a preference is used in the regression analyses to prevent multicollinearity. Last, to obtain proper insight in the effect of life-styles, traditional and sociocultural predictors with low and insignificant weights are removed so that these minor effects do not detract from those of more important predictors and of life-styles in the final analyses (see Garson 2010). This is accomplished by selecting the relevant traditional predictors in a preliminary stepwise regression analysis and entering that selection in a subsequent analysis in which sociocultural variables in their turn are selected using a stepwise procedure. The last stage involves the stepwise addition of life-styles to the other sets (cf. the design in Sect. 3). This process is repeated for each preference.

Dwelling preferences that are excluded because they show too little variance or lack a relation with life-styles concern the following: all dwelling types; the number of bedrooms; having the main living spaces on the same floor; the presence of a bathtub; the location of the toilets; the form of the kitchen and the outside space; and the tenure (15 out of 16). Of the neighborhood preferences, 31 out of 39 are omitted for the same reasons: living in another area; liveliness; the diversity of buildings; accessibility by car and public transport; the amount of green space; neighborhood reputation; the presence of mixed functions (living, shopping and working); suitability for children; most of the facilities (for health care, play, sports, youth and elderly people); the amount of parking space; all aggregated types in the classification of residential environments (woonmilieus); the frequency of interpersonal contact; and the degree of similarity among residents (regarding cultural background, opinions, education, the willingness to look out for or help each other, age and household composition; the latter aspects are discussed below in response to the second question). Two more preferences were deleted (frequent neighborhood activities and information on activities) because they seemed too closely related to one indicator of lifestyles (take part in activities).

Table 2 shows the results for the remaining preferences (one related to the dwelling and six to the neighborhood). This information differs from the customary output of logistic regression. The study is not intended to predict specific preferences in this particular case. Accordingly, individual weights or odds ratios are not specified because they provide no insight in the contribution of life-styles to the previously entered traditional and/or sociocultural variables as a group. The first objective of the study requires a comparison of the strength of association of regression models with and without life-styles. Common 
Table 2 Contributions of life-styles to remaining preferences

\begin{tabular}{|c|c|c|c|c|c|c|c|c|}
\hline Preference & $\mathrm{N}$ & Predictors & $\mathrm{R}^{2}$ & $\% 0$ & $\% \mathrm{~T}$ & $\Delta \mathrm{T}$ & $\Delta \mathrm{S}$ & $\Delta \mathrm{L}$ \\
\hline Only shower & 1,928 & $\mathrm{a}, \mathrm{h}, \mathrm{n}, \mathrm{lad}, \mathrm{tf}, \mathrm{tg}$ & .268 & 54.9 & 70.4 & 14.5 & 1.0 & - \\
\hline Place of worship & 1,474 & $\mathrm{a}, \mathrm{e}, \mathrm{m}, \mathrm{p}, \mathrm{r}, \mathrm{c}, \mathrm{ldp}, \mathrm{sl}, \mathrm{L}$ & .369 & 61.8 & 74.8 & 3.1 & 9.0 & .9 \\
\hline Own neighborhood & 1,537 & $\mathrm{a}, \mathrm{e}, \mathrm{p}, \mathrm{r}, \mathrm{lt}, \mathrm{L}$ & .173 & 53.3 & 66.0 & 8.9 & 2.3 & 1.5 \\
\hline Primary school & 1,482 & $\mathrm{a}, \mathrm{h}, \mathrm{m}, \mathrm{p}, \mathrm{r}, \mathrm{la}, \mathrm{L}$ & .202 & 51.0 & 66.5 & 12.4 & 1.3 & 1.8 \\
\hline Nursery & 1,480 & $\mathrm{a}, \mathrm{h}, \mathrm{m}, \mathrm{p}, \mathrm{r}, \mathrm{lag}, \mathrm{L}$ & .136 & 56.1 & 65.0 & 5.5 & 1.4 & 2.0 \\
\hline Move within neighborhood & 1,782 & $\mathrm{e}, \mathrm{h}, \mathrm{n}, \mathrm{sl}, \mathrm{L}$ & .070 & 53.7 & 60.3 & 2.0 & 2.4 & 2.2 \\
\hline Meeting place & 1,530 & $\mathrm{a}, \mathrm{p}, \mathrm{r}, \mathrm{lv}, \mathrm{sl}, \mathrm{L}$ & .171 & 56.9 & 65.2 & 2.4 & 1.9 & 4.0 \\
\hline
\end{tabular}

Traditional predictors (categories): $a$ age (6), $e$ education (6), $h$ household size (4), $m$ main daily activity/ profession (5), la leisure activities amusement parks (2), ld leisure activities dancing/pub (2), $l g$ leisure activities gardening (2), lp leisure activities place of worship/church (2), lt leisure activities trips (2)

Sociocultural predictors (categories): $p$ political affiliation (6), $n$ newspaper (6), $r$ religious affiliation (3), $c$ cultural affiliation (2), $l v$ leisure activities voluntary work (2), $t f$ television programs films (2), $t g$ television guide (4), $s l$ television station local (2), $L$ life-styles (5)

measures of this overall effect size are pseudo- $\mathrm{R}^{2}$ and the percentage of correctly predicted cases in the classification tables. These measures allow the monitoring of their change in exploratory sequential regression analyses. Both methods have shortcomings but classification percentages are generally preferred to $R^{2}$ (Garson 2010). Thus, classification is used as the main test of effect size and $\mathrm{R}^{2}$ (Nagelkerke) as an additional measure. The last five columns contain the percentages in a model without predictors (solely based on the observed proportions), the percentage predicted by the total model with all relevant predictors included, and the increase of the predicted percentage as a result of adding traditional, sociocultural and life-style predictors, respectively. The first three columns display the preferences, the size of the test sample and the predictor variables (these are explained below the table). Other results are discussed in the text.

The preferences in the table are dichotomous. Binary logistic regression shows that all models match the observed data (Hosmer and Lemeshow goodness-of-fit tests are not significant) and that the sets of predictors in the intermediate and the final models are adequately related to the preferences (Omnibus $\chi^{2}$ values are significant at .001 ). The sample size has decreased due to listwise deletion of missing values, especially when political affiliation is one of the predictors (which is a relatively sensitive theme). The percentages of correctly predicted cases in the final models have increased by between 6.4 and $15.5 \%$ and the values of $\mathrm{R}^{2}$ show the same trend. Traditional variables contribute up to $14.5 \%$ (on average $7.0 \%$ ) with age, education, household size and main daily activity as predictors. Sociocultural variables have less influence (1-9\%; mean 2.8\%). They consist mostly of political and religious affiliation, favorite newspaper, various leisure activities and local television as the principal channel. Most relations between predictors and preferences are natural. For example, the elderly (with smaller households) frequently prefer a separate shower to a bath. The presence of a place of worship is valued by religious people who mention attending services as a leisure activity. A school or nursery is important to families with children (hence the link with age and household size). An interest in local affairs (shown by a local television station) is related to preferences for a meeting place.

In the final step life-styles add between 0 and $4 \%$ (mean 1.8\%). These fractions are up to $5 \%$ lower than in regression analyses with life-styles as the only predictor (not shown in 
the table). This indicates that some of the variance (or information), shared by life-styles and preferences is now represented in the other variables. Tests of these common effects (Fig. 1, link d) reveal that life-styles are associated with age, main daily activity and household composition. Quiet citizens are often older, retired and living alone or with a partner, while mediators are younger, working and belong to a larger family with children $\left(83<\chi^{2}<138 ; 12<\mathrm{df}<20 ; P<.001\right)$. The first group also has more explicit political and religious orientations and mentions fewer outdoor leisure activities $\left(19<\chi^{2}<74\right.$; $4<$ df $<20 ; P<.001)$. As a result, these traditional and sociocultural variables cause lifestyles to be somewhat redundant in most analyses: their residual contributions are small (or even insignificant) compared to the joint influences of the other predictors. In one case (preference for a meeting place) the input is somewhat larger. In search of an explanation it became apparent that this larger proportion is (again) mainly attributable to differences between quiet citizens and mediators. The latter group is likely to prefer a meeting place and the former group is not $\left(128<\chi^{2}<415\right.$; $\left.\mathrm{df}=4 ; P<.001\right)$. Presumably, this effect is not related to the life-styles as a whole (the composite variable) but to one of the indicators: mediators are inclined to take part in neighborhood activities and quiet citizens do not have that intention.

\subsection{Life-styles and preferred types of housing and environment}

The assumption that life-style groups prefer specific aggregated types of housing and residential environment (woonmilieus) was tested in two ways. First, the current circumstances may reveal a relationship with life-styles. Questions were asked about the present location (city or village), the type of dwelling, the year of construction and the rent paid. Results of $\chi^{2}$ and regression analyses show that life-styles are not associated with these aspects. It is possible that life-style groups do have such preferences but that those ambitions could not be fulfilled due to certain constraints in the past. This issue is avoided in a second set of questions about preferences regarding a future location and the aggregated types of housing and environment (woonmilieus) in the official classification of the city of Eindhoven. Now, answers should only be limited by actual financial possibilities to prevent unrealistic choices and not by other matters such as the availability of dwellings or the proximity of work or family and friends. Again, there is no relation between life-styles and most preferences. In a single case (a preference to stay in their own present neighborhood; see Table 2) life-styles have some unique predictive value, but this is minor $(1.5 \%)$ compared to the contribution of traditional and sociocultural variables $(11.2 \%)$.

\subsection{Homogeneous life-style settings}

Preferences for homogeneous versus heterogeneous settings were measured with five questions on the importance of similarity among neighborhood residents with respect to sociodemographic and sociocultural characteristics (age, level of education/income, household composition, general opinions and cultural background). On average, all of these features are not very important (approximately 2 on a four-point scale ranging from 1: unimportant to 4: important). There is no evidence supporting the assumption that lifestyle groups prefer homogeneous settings. The only significant result is that quiet citizens more often prefer neighbors of about the same age as theirs (Kruskal-Wallis: $\chi^{2}=26.8$; $\mathrm{df}=4 ; P<.001)$. This, however, is caused by age as a traditional variable and not by lifestyles. Especially people over 65 mention this preference $\left(\chi^{2}=86.6\right.$; $\left.\mathrm{df}=1 ; P<.001\right)$ and life-style effects are hardly visible in a regression analysis while traditional and 
sociocultural variables (age, education, political orientation and leisure activities) have some effect $(2.9 \%$ more correctly predicted cases).

\section{Conclusions}

The purpose of the study was to test three main assumptions underlying the belief of housing providers and commercial agencies that life-style research is essential to gain more insight in the demand side of the housing market. These assumptions are as follows: that the standard demographic and socioeconomic variables are no longer adequate to explain and predict residential preferences due to the increased complexity of contemporary society; that life-style groups favor specific aggregated types of housing and environment (woonmilieus); and that citizens in general and these groups in particular prefer to live in homogeneous life-style settings. The study used a large sample, indicators that fit both the theory and the descriptions of the life-style groups, a new taxonomy method that was effective and a successful validity check of the method and the group composition. Shortcomings are that the sample contains slightly more elderly and no migrants who hold only a foreign passport. These deficiencies appear to have no significant adverse consequences.

As for the life-styles used by this housing association, the results clearly show that the assumptions are unjustified. A majority of the preferences regarding the dwelling and the environment (46 out of 55) are not related to life-styles. In most of the remaining cases traditional variables combined with some basic sociocultural characteristics contain roughly the same information on preferences as life-styles so their necessity is doubtful. The somewhat larger impact on one preference is caused by one indicator; it does not show the necessity of life-styles as a composite variable. There is no proof that life-style groups favor specific aggregated types of housing and environment (woonmilieus), and neither tenants in general nor life-style groups regard demographic and sociocultural homogeneity of settings as important.

The last result can probably be generalized to a larger population because it concerns all tenants and not only life-style groups. But this is not possible for the other results due to the variety of definitions, indicators and composition of life-styles. Because a similar systematic test of every possible life-style classification would be unfeasible, a different approach is needed to evaluate whether life-styles may generally be necessary for planning and housing policy. The outcomes of the study and the line of argument during the analyses give rise to the following tentative observations.

First, life-styles should only replace traditional variables if it is clear that the relevant information on housing preferences or choice behavior contained in these variables is also represented in the life-styles. The current results suggest that this is not likely: a large number of preferences are dependent on demographic variables and not on life-styles. This will probably also be true when different types of life-style are employed, unless the traditional variables are integrated in the life-styles as indicators. Then, of course, their necessity should appear from a stronger association between this composite predictor and the preferences compared with the joint influences of separate traditional and life-style predictors on those preferences. This is doubtful and such integration is also undesirable (see below). In addition, traditional variables will still be needed for other purposes (e.g. the statistical control of context effects or the fine-tuning of client groups; see Heijs et al. 2005). Therefore, it is plausible that life-styles are mainly usable as a supplement to traditional variables. 
Second, adopting a role as a supplement is only useful if life-styles contain information that is not available in the traditional variables. The amount of common information (that is already part of the traditional variables) can be substantial. This study shows, for example, that including traditional predictors can make life-styles redundant. Because it is not inconceivable that most current life-style indicators (and therefore life-styles) are to some extent related to traditional variables, there is a chance that the contribution is low in other situations as well.

Third, in the construction of composite variables like life-styles valuable information contained in the indicator variables may be lost. Cluster analyses or scaling methods, for instance, often involve compromise (e.g. a reduction in the number of dimensions or a degree of subjectivity in the demarcation of the groups; see Sect. 3). Additionally, these methods are not aimed at an optimal prediction of a dependent variable (housing preference) but at an optimal configuration of all variables involved. This may well be a configuration that only partly reflects the information that is shared between the indicators and the dependent variable. A model-based approach deals with a limited number of indicators. Again, compromise is needed: some indicators are retained while others are disregarded with a view to the theoretical perspective or a feasible analysis. In either case, the amount of relevant information in a life-style variable (consisting of clusters or combinations of indicators in a model) is generally less than the total amount of relevant information in the collection of indicator variables. Furthermore, a composite life-style variable can obscure the input of separate indicators. One indicator may be responsible for an effect that could be wrongfully interpreted as a contribution of life-styles as a whole (see Sect. 4). Effects from different subsets of indicators are also not easily traced back to these subsets. This inhibits the formulation of proper explanations. In summary, to arrive at an optimal explanation and prediction of preferences for planning, it is advisable to use independent variables with a potential bearing on those preferences as separate predictors and not as indicators (that will be replaced by the composite variable) in order to take full advantage of their possible contribution (like sociocultural variables in this study).

According to these observations, the necessity of life-styles is probably doubtful in other situations as well. There is conclusive evidence of the importance of traditional variables as separate predictors. The information contained in those variables reduces the share of life-styles in the prediction of housing preferences. When other relevant predictors are introduced or when significant indicators are transformed into separate predictors to increase their effectiveness or to reveal that they are the real cause of the predictive quality of a life-style variable, that share becomes even smaller. These statements are corroborated by the results of the current project. In view of the additional fact that it is less problematic to operationalize and measure single predictors, it seems that life-styles should probably not be the primary choice in applied research for policy and planning. Of course, different considerations apply when the research has a theoretical interest (e.g. when using a modelbased composite variable to study interaction effects).

The question remains how the explanation and prediction of housing preferences can be enhanced. The need for further improvement is illustrated by the proportions of incorrectly classified preferences in this study. With traditional variables as the only predictors these proportions range from 17 to $43 \%$ (across all preferences). Part of this residual variation is attributable to unsystematic individual differences (statistical error). The prediction of the other part can be increased by adding sociocultural variables like those that were used here to identify: (1) the affinity to certain societal groups (such as religion, political party or ethnic/cultural background); (2) certain activities in the home or the neighborhood. There appears to be no obvious reason to refrain from using variables in the first category: those 
aspects are known and they are assessable in the same manner as traditional variables. Variables in the second group are less well defined, yet, as this study shows, daily activities can be a valuable resource. That is because they not only improve the prediction rate but also provide a better understanding of the dwelling processes that directly motivate specific preferences (see Sect. 4). This knowledge of motives/processes may provide the improvement of prediction rates that is sought in order to allow for better decision-making. The current set of activities in the sociocultural variables (and life-style indicators) is a first attempt that results in a moderate contribution (an increase of up to 10\%). It is likely that this contribution would be higher with a more comprehensive set. Future research should establish which activities are relevant and which level of aggregation is appropriate for general application. (A structured method to take inventory of concrete dwelling activities is described in Heijs 2007.)

Open Access This article is distributed under the terms of the Creative Commons Attribution Noncommercial License which permits any noncommercial use, distribution, and reproduction in any medium, provided the original author(s) and source are credited.

\section{References}

Ajzen, I. (1991). The theory of planned behavior. Organizational Behavior and Human Decision Processes, $50,179-211$.

Ajzen, I. (2001). Nature and operation of attitudes. Annual Reviews of Psychology, 52, 27-58.

Bastiaansen, I. (1997). Leefstijlen als basis voor het nieuwe wonen. In J. Broess \& C. Grijzen (Eds.), Brabant ongemonteerd (pp. 5-20). Den Bosch: Projectburo Brabant 2050.

Brouwer, J. (1998). Leefstijlen en woonmilieus. Delft: ABF.

de Jong, F. (1996). Woonvoorkeuronderzoek: theorie, empirie en relevantie voor de praktijk. Woonconsument en woningkwaliteit 5. Delft: Technische Universiteit Delft, Faculteit Bouwkunde.

de Wijs-Mulkens, E. (1999). Wonen op stand. Lifestyles en landschappen van de culturele en economische elite. Amsterdam: het Spinhuis.

Ganzeboom, H. (1988). Leefstijlen in Nederland: een verkennende studie. Den Haag: Sociaal Cultureel Planbureau.

Garson, G. (2010). Logistic regression. Retrieved April 29, 2010, from North Carolina State University, College of Humanities and Social Sciences Website: http://faculty.chass.ncsu.edu/garson/PA765/ logistic.htm.

Hagen, G. (2001). Motivational profiling in de woningmarkt. Tijdschrift voor de Volkshuisvesting, 3, 6-11.

Heijs, W. (2007). User needs analysis and bridging the application gap. In E. Edgerton, O. Romice, \& C. Spencer (Eds.), Environmental psychology: Putting research into practice (pp. 30-43). Newcastle: Cambridge Scholars Publishing.

Heijs, W., Carton, M., Smeets, J., \& van Gemert, A. (2005). Labyrint van Leefstijlen. In: Handboek stedelijk management (pp. A4-9-1-A4-9-50). 's Gravenhage: Elsevier Overheid.

Heijs, W., Carton, M., Smeets, J., \& van Gemert, A. (2009). The labyrinth of life-styles. Journal of Housing and the Built Environment, 24, 347-356.

Kahle, L., Beatty, S., \& Homer, P. (1986). Alternative measurement approaches to consumer values: The list of values (LOV) and values and life style (VALS). Journal of Consumer Research, 13, 405-409.

Kahle, L., \& Chiagouris, L. (1997). Values, lifestyles and psychographics. Mahwah: Lawrence Erlbaum.

Maio, G., Olsen, J., Bernard, M., \& Luke, M. (2003). Ideologies, values, attitudes, and behavior. In: J. Delamater (Ed.). Handbook of social psychology (pp. 283-308). New York: Kluwer Academic/ Plenum Publishers.

Nio, I. (2002). Van levenswijzen tot lifestyles: over de bruikbaarheid van leefstijlen voor de ruimtelijke ordening. Stedebouw and Ruimtelijke Ordening, 83, 6-10.

Ouwehand, A. (2001). Een wijk is geen auto. Tijdschrift voor de Volkshuisvesting, 7, 10-15.

Pinkster, F., \& van Kempen, R. (2002). Leefstijlen en woonmilieuvoorkeuren. Utrecht: Urban and Regional Research Centre, Universiteit Utrecht.

Reijndorp, A., Kompier, V., \& de Haas, L. (1997). Leefstijlen. Wonen in de 21ste eeuw. Rotterdam: NAi. 
Smeets, J. (2010). Sturen op klantwaarde. Instrumenten voor woningcorporaties ten behoeve van een vraaggericht assetmanagement. Dissertation. Bouwstenen 137, Eindhoven: University of Technology. van der Wouden, R., \& Kullberg, J. (2002). Stijloefeningen: leefstijlen in onderzoek en praktijk. Stedebouw and Ruimtelijke Ordening, 83, 10-20.

van Deursen, A., \& Leussink, M. (2010). Leefstijlen in het WoonDOMEIN? Master thesis. Real Estate Management and Development. Department of Architecture, Building and Planning, Eindhoven: University of Technology.

van Diepen, V., \& Arnoldus, M. (2003). De woonvraag in de vraaggestuurde markt. Amsterdam: DGW/ NETHUR.

van Diepen, A., \& Musterd, S. (2001). Stedelijke leefstijlen en woonmilieus in Amsterdam. Amsterdam: Amsterdam Study Centre for the Metropolitan Environment.

van Diepen, A., \& Musterd, S. (2009). Lifestyles and the city: Connecting daily life to urbanity. Journal of Housing and the Built Environment, 24, 331-345.

Vijgen, J., \& Van Engelsdorp Gastelaars, R. (1986). Stedelijke bevolkingscategorieën in opkomst: Stijlen en strategieën in het alledaagse bestaan. Amsterdam: Koninklijk Nederlands Aardrijkskundig Genootschap. 